\title{
UPAYA PENINGKATAN KUALITAS DAN HASIL PRODUKSI SABLON, KONVEKSI DAN BORDIR GILDAN.BDG KABUPATEN BANDUNG
}

\author{
Hanifah \\ hanifahoney@gmail.com \\ Novi Kadarini Rahayu \\ trengginasina@gmail.com \\ Hery Haerudin \\ heryhaerudin@gmail.com
}

\section{SEKOLAH TINGGI ILMU EKONOMI (STIE) EKUITAS}

\begin{abstract}
ABSTRAK
UMKM (Usaha Mikro Kecil Menengah) sebagai salah satu wadah usaha masyarakat Indonesia memiliki peran penting dalam perekonomian Indonesia, yang merupakan cikal bakal usaha besar. Sebagian besar usaha yang berkembang di Indonesia berawal dari UMKM (Usaha Mikro Kecil Menengah), sehingga UMKM ini harus terus dikembangkan agar terus maju dan mempunyai daya saing dengan usaha-usaha besar, agar keberadaannya menjadi jantung perekonomian masyarakat Indonesia. Dalam perkembangannya UMKM memiliki beberapa permasalahan diantaranya belum menguasai manajemen, belum paham bagaimana meningkatkan kualitas produksi, dan masih kurang memahaminya pembukuan. Tujuan pelaksanaan program PKM ini adalah untuk meningkatkan kualitas produksi sablon, pemasaran dan pembukuan sederhana konveksi dan bordir GILDAN.BANDUNG. Metode pelaksanaan kegiatan ini terdiri dari empat tahapan, yaitu: perencanaan program (survey dan wawancara), pelaksanaan program (memberikan pelatihan dengan praktik langsung), evaluasi, dan refleksi (program pendampingan). Setelah melakukan kegiatan tersebut kualitas dan kuantitas produk GILDAN.BDG meningkat.
\end{abstract}

Kata kunci: UMKM, Kualitas Produksi, Sablon Dan Border Gildan Bandung

\section{PENDAHULUAN}

\subsection{Analisis Situasi}

UMKM memiliki peranan penting dalam lajunya perekonomian masyarakat di Indonesia. UMKM ini memiliki kontribusi yang sangat besar kepada pemerintah yaitu sebagai pendapatan negara khususnya dalam menciptakan lapangan pekerjaan. Dengan demikian UMKM selayaknya mendapat perhatian khusus dan dukungan yang terarah.
Menurut Iman dan Adi (2009), UMKM di Indonesia memiliki kemampuan yang sangat luas dalam membuka lapangan pekerjaan, sehingga sangat membantu dalam meningkatkan pendapatan perkapita masyarakat, mendorong perkembangan atau pertumbuhan ekonomi, secara keseluruhan dapat mewujudkan tingkat stabiltas perekonomian masyarakat nasional.

Kinerja UMKM saat ini walaupun memiliki kontribusi yang besar, 
tapi para UMKM tersebut memiliki tingkat produktifitas yang relative masih rendah, kurangnya perhatian terhadap kualitas, bahkan kadang-kadang yang dikejar adalah kuantitas, begitu juga manajemen bagaimana merencanakan, mengkomunikasikan, mengkoordinasikan antara pegawai , aktivitas dan pengontrolan pada dasarnya masih kurang optimal dimiliki oleh para UMKM (Andang, 2007) dalam afifah (2012), hal ini senantiasa harusnya menjadi perhatian.

Selain itu masalah pembukuan pada umumnya belum dipahami oleh para UMKM, padahal pembukuan ini merupakan suatu hal yang sangat penting untuk pengambilan keputusan. Jika permasalahanpermasalahn ini dibiarkan terus menerus, maka semakin lama UMKM ini semakin menurun, otomatis kontribusi terhadap pemerintah menjadi menurun.

Seperti halnya permasalahan yang dihadapi oleh UMKM GILDAN BANDUNG yang kami survey. UMKM ini memiliki permasalahan pertama harus jika pesanan banyak harus mencari dana talangan terlebih dahulu, masalah kedua adalah masalah desain dan kualitas produksi yang bisa bersaing di pasaran, masalah ketiga adalah masalah pemasaran, sehingga produksi UMKM ini belum diketahui oleh kalangan yang lebih luas, dan masalah keempat adalah masalah pencatatan keuangan UMKM, selama ini masih menggunakan pencatatan yang sangat sederhana, sehingga perusahaan sulit untuk mengetahui aliran kas secara pasti, sehingga sulit untuk menetukan laba, atau harga jual produknya.

\subsection{Identifikasi Masalah}

Dilihat dari analisis situasi dan latar belakang masalah pada Produksi, Sablon, Konveksi dan Bordir GILDAN.BANDUNG sebagai mitra dalam pelaksanaan PKM ini, maka dapat dirumuskan permasalahan yang ada antara lain adalah : (1) Belum menguasai dan paham bagaimana meningkatkan kualitas dan produksi (2) belum memahami pemasaran yang efektif
(3) Belum memahaminya pembukuan sederhana (3)

\section{METODOLOGI PELAKSANAAN}

\subsection{Target}

Program Pengabdian Masyarakat ini sasarannya adalah UMKM yang bergerak di bidang Produksi, Sablon, Konveksi dan Bordir, GILDAN.BANDUNG , yang berlokasi di jalan pasir impun komplek bukit padjajaran no. 80 Kabupaten Bandung.

\subsection{Luaran}

Pada hakekatnya, kegiatan pengabdian kepada masyarakat ini merupakan solusi terhadap permasalahan yang dihadapi mitra melalui pendekatan secara terpadu, agar dapat memberikan keterampilan dalam meningkatkan kualitas dan hasil produksi Sablon, Konveksi dan Bordir GILDAN.BANDUNG. selain itu meningkatkan pemasaran dan pemahaman pembukuan. Adapun luaran yang diharapkan dari Program Pengabdian ini adalah sebagai berikut.

a. Peningkatan kualitas produksi Sablon, Konveksi dan Bordir GILDAN.BANDUNG.

b. Pelatihan memasarkan hasil produksi, Sablon, Konveksi dan Bordir GILDAN BANDUNG

c. Pelatihan peningkatan pemahaman pembukuan sederhana

\section{HASIL DAN LUARAN}

3.1 Solusi yang ditawarkan

Berdasarkan permasalahan yang dihadapi oleh mitra seperti tertulis dalam bab sebelumnya, beberapa alternatif solusi yang dapat ditawarkan adalah:

3.2 Mekanisme Pelaksanaan

Rancangan mekanisme pelaksanaan kegiatan program ini dilakukan dengan mengadopsi langkah-langkah action research yang terdiri dari 4 (empat) tahapan, yaitu: perencanaan, tindakan, evaluasi, dan refleksi. Kegiatan-kegiatan atau aktivitasaktivitas dari masing-masing tahapan adalah sebagai berikut: 


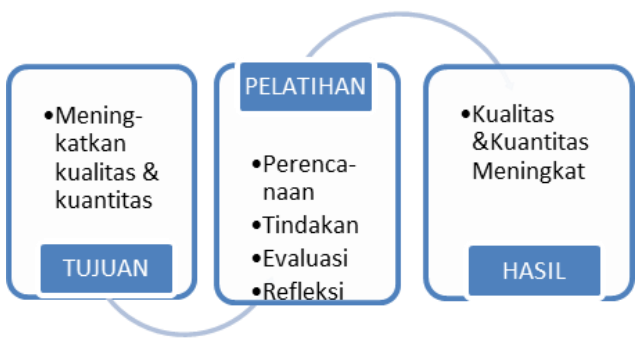

a. Perencanaan

Perencanaan dilakukan dalam beberapa kegiatan seperti mengumpulkan data dan informasi mengenai masalah-masalah, kelemahan termasuk melihat peluang apa yang dikembangkan dari seluruh potensial pada mitra program, kekuatan dan ancaman mitra dalam usahanya.

b. Tindakan

Tindakan dalam kegiatan ini adalah melaksanakan pelatihan kualitas Produksi, pelatihan peningkatan pemasaran, dan pembukuan sederhana pada Sablon, Konveksi dan Bordir GILDAN. BANDUNG.

c. Evaluasi

Evaluasi terhadap implementasi program, yaitu evaluasi terhadap proses peningkatan kualitas dan hasil produksi Sablon, pemasaran dan pembukuan sederhana Konveksi dan Bordir GILDAN.BANDUNG.

d. Refleksi

Refleksi dilakukan untuk mengetahui kesesuaian antara kondisi dengan yang diharapkan atau kriteria, sehingga kita dapat menetapkan rekomendasi terhadap keberlangsungan atau pengembangan kegiatan-kegiatan berikutnya. termasuk dengan memberikan pendampingan, untuk mengetahui sejauh mana keberhasilan program yang telah dilaksanakan efektif

\section{KESIMPULAN DAN SARAN}

Program kemitraan masyarakat (PKM) peningkatan kemampuan produksi pada kelompok usaha manufaktur logam telah dilaksanakan. Untuk dapat meningkatkan kemampuan produksinya, selain mendukung pengadaan fasilitas pendukung produksi yang diperlukan berupa mesin gerinda/ pengasah pahat, serangkaian pelatihan dalam aspek teknikal dan manajerial yang diperkuat dengan pendampingan di lapangan adalah merupakan kegiatan inti dalam program ini. Kerjasama yang baik serta partisipasi aktif dari mitra PKM mendukung kelancaran dan keberhasilan pelaksanaan program ini. Selain ketrampilan dan kemampuan praktis dari operator mesin dalam hal pengoperasian mesin perkakas dan pemilihan pahat yang diperlukan, ketrampilan dalam penggerindaan dan pengasahan pahat yang aus ataupun yang perlu dibentuk juga meningkat. Sementara kemampuan dari pengelola/ penanggung jawab produksi mitra PKM juga meningkat, meliputi pengaturan/ penjadwalan kerja serta menghitung/ menetukan biaya produksi. Sehingga secara umum dapat dikatakan bahwa program ini berjalan lancar dan sukses dalam upaya meningkatkan kemampuan produksi dari mitra PKM, walaupun untuk hasil yang signifikan masih diperlukan lebih banyak waktu lagi.

Selain itu, untuk tahapan program berikutnya perlu diberikan juga penguatan aspek teknikal dalam hal yang lain (misal: kemampuan dalam desain) serta pendampingan yang berkesinambunagan dapat terus dilakukan dalam konteks mitra binaan.

\section{DAFTAR PUSTAKA}

Setyawan, F.B. (2011). Pengaruh Geometri Sudut Pahat High Speed Steel (HSS) Terhadap Umur Pahat dan Penyusunan Standart Operational Procedure (SOP) Pengasahan Pahat 
Pada Proses Bubut Aluminium Paduan Rendah. Skripsi. Surakarta: Jurusan Teknik Industri Fakultas Teknik, Universitas Sebelas Maret.

Prayogo, W. (2012). Pengaruh Variasi Sudut Potong dan Sudut Buang Pahat Baja ASSAB ASP 23/VANADIS 23 Terhadap Tingkat Kualitas Permukaan Benda Kerja. Skripsi, Jurusan Teknik Mesin, Fakultas Teknik, Universitas Negeri Malang.

Riduwan, M. (2013). Pengaruh Sudut Pahat Bubut (Side Rake Angle) Terhadap Kekasaran Permukaan Baja St 42 Pada Proses Bubut. Skripsi. Program Studi Teknik Mesin, Fakultas Teknik, Universitas Jember.

Fata, A., Nikuei, B. (2010). The Effect of the Tool Geometry and Cutting Conditions on the Tool Deflection and Cutting Forces. International Journal of Mechanical, Aerospace, Industrial, Mechatronic and Manufacturing Engineering Vol. 4, No. 9.

Kumari, K.V., Santha., Jana, D. R., and Kumar, A., (2010). Effects of Tool Setting on Tool Cutting Angle on Turning Operation. ARPN Journal of Engineering and Applied Sciences, Vol. 5, No. 5, 27-31.

Dogra, M., Sharma, V. S., Dureja, J., (2011). Effect of Tool Geometry Variation on Finish Turning - A Review. Journal of Engineering Science and Technology Review 4 (1), pp 1-13.

Conradie, P.J.T., Oosthuizen G,A., Dimitrov DM., Saxer, M. (2015). Effect Of Milling Strategy And Tool Geometry On Machining Cost When Cutting Titanium Alloys. South African
Journal of Industrial Engineering, Vol 26(3) pp 137-151.

Akhilesh, P. S., \& Er, R. B. S. (2016). In Metal Turning, Effect of Tool Rakes Angles and Lubricants on Cutting Tool Life and Surface Finish: A Review. International Research Journal of Engineering and Technology, Vol: 03 Issue: 02, pp 696700 .

Kadirgama, K., Abou-El-Hossein, K.A., Noor,M.M., Sharma, K.V., Mohammad, B., (2011). Tool Life And Wear Mechanism When Machining Hastelloy C-22HS. Wear, 270: pp 258-268.

Sharma, K., Mahto, D., and Sen, S.S. (2013). In metal turning, effect of various parameters on cutting tool: A Review. International Journal of Application or Innovation in Engineering \& Management, Vol: 2, Issue: 8, pp 3238.

Ojolo, S. J., Ogunkomaiya, O. (2014). A Study of Effects of Machining Parameters on Tool Life. International Journal of Materials Science and Applications; 3(5): 183199 , doi: 10.11648/j.ijmsa.20140305.19.

Hietikko, E. (2012). Estimation of Manufacturing Costs in the Early Stages of Product Development Project. International Journal of Modern Engineering Research, Vol. 2, Issue. 6, pp-4673-4676.

Aurora, B.C. (2013). The Cost of Production Under Direct Costing and Absorption Costing - A Comparative Approach, Annals of the „Constantin Brâncuşi”” 
University of Târgu Jiu. Economy

Series, Issue 2, pp 123-129. 